\title{
LA TRADUCCIÓN DEL HUMOR AUDIOVISUAL. EL CASO DE LA PELÍCULA DE ANIMACIÓN EL ESPANTATIBURONES (SHARK TALE)
}

\author{
María Lucía Navarro Brotons \\ lucia.navarro@ua.es \\ Universidad de Alicante
}

\section{Resumen}

En el presente trabajo nos disponemos a hacer un análisis del doblaje al español de la película de dibujos animados El Espantatiburones, cuyo título original es Shark Tale. El análisis consistirá en estudiar los recursos humorísticos del texto origen, ver el tipo de problemas que presentan a la hora de realizar su doblaje para, por último, analizar cómo ha actuado el traductor ante los mismos. La elección de esta película no es fortuita, pues se trata de un film que ofrece diferentes dificultades de traducción a la hora del doblaje al español: gran cantidad de referentes culturales, ingeniosos juegos de palabras vinculados al sema visual, palabras inventadas (coinages...) e intertextualidades, entre otros.

\begin{abstract}
"The translation of audiovisual humour. The case of the animated film Shark Tale (El Espantatiburones)"

In this paper, we analyse the Spanish dubbed version of the animated film El Espantatiburones whose original title is Shark Tale. The analysis will consist of studying the humoristic resources of the source text, seeing the kind of problems that arise when translating it for the dubbed version, and, finally, analysing how the translator has acted in dealing with them. The choice of this film is not fortuitous since it offers different translation difficulties for dubbing it in Spanish: numerous cultural references, witty puns related to the visual seme, invented words or coinages and intertextuality, among others.
\end{abstract}


Palabras clave: Traducción audiovisual. Humor. Doblaje. Películas de animación. Análisis traductológico.

Keywords: Audiovisual translation. Humour. Dubbing. Animated films. Translational analysis.

Manuscript received on June 30, 2016 and accepted for publication on September 27, 2016.

Para enlazar con este artículo / To link to this article:

http://dx.doi.org/10.6035/MonTI.2017.9.11

Para citar este artículo / To cite this article:

NAVARRo Brotons, María Lucía. (2017) "La traducción del humor en el medio audiovisual. El caso de la película de animación El Espantatiburones (Shark Tale)." In: Martínez Sierra, Juan José \& Patrick Zabalbeascoa Terran (eds.) 2017. The Translation of Humour / La traducción del humor. MonTI 9, pp. 307-329. 


\section{La traducción audiovisual}

La traducción audiovisual es una de las modalidades de traducción más demandadas actualmente debido a que durante los últimos años del siglo XX y los primeros del XXI hemos asistido a un boom de textos audiovisuales destinados al entretenimiento y a la información (cf. Martínez Sierra 2012: 11 y Mayoral 2001: 20). El auge de este tipo de traducción en nuestro país no es de extrañar debido a que se importan muchos productos audiovisuales cuya lengua original no es la española, de hecho, como dicen Santos Redondo \& Montás Betances (2010) "Cerca del 85\% del cine que se consume en España es importado, principalmente desde Estados Unidos [...] y, en menor medida, de otros países europeos".

A finales de la segunda mitad del siglo XX empiezan a aparecer referencias a la traducción audiovisual en trabajos académicos que versan sobre la traducción en general. Sin embargo, esta fuerte demanda de traducción audiovisual de la que hablamos ha provocado que en los últimos años la investigación sobre esta modalidad haya aumentado considerablemente. Trabajos como los de Gambier (1994), Agost (1996) y Chaume (2000), entre otros, dan buena cuenta de ello.

La traducción audiovisual abarca diversos medios entre los que destacamos: cine, vídeo y DVD, televisión y productos multimedia. Todos ellos tienen unos factores y características comunes dentro del campo de la traducción, ya que ofrecen una emisión del contenido mediante dos canales: el audio y el visual, combinando dos códigos de signos: el verbal y el no verbal. Además, es de vital importancia la sincronización de los mismos por tratarse de códigos que no son autónomos. Así, encontramos el código visual que permanece invariable frente al código lingüístico que es el que ha de ser traducido (cf. Hurtado Albir 2001). Como señala Zabalbeascoa (2001a: 120):

[...] el texto audiovisual prototípico es el que emplea todos sus signos de tal manera que forman un entramado que es el que da coherencia al texto, y se hace imposible, desde este punto de vista, analizar ningún elemento por separado de los demás componentes textuales. 
Cabe tener en cuenta también que una versión doblada de un audiovisual no la realiza únicamente el traductor:

[...] es importante recordar que el papel del traductor en la mayoría de los casos se limita a la propuesta de un primer borrador escrito de lo que podríamos llamar el guión de la versión doblada. (Zabalbeascoa 2001b: 252).

En el proceso, por lo tanto, intervienen los ajustadores, el director y los actores de doblaje. Por lo tanto, el guion puede sufrir alteraciones por parte de estos profesionales que pueden, o no, conocer la lengua original del producto con el que están trabajando.

\section{La traducción del humor en el medio audiovisual}

Si queremos entender la traducción del humor en los textos audiovisuales es primordial conocer, por una parte, los elementos propios de la traducción audiovisual y, por otra, los de la traducción del humor (cf. Fuentes Luque 2000), pues cuando hablamos de traducción de textos audiovisuales relacionados con la comicidad debemos añadir a las restricciones propias de la traducción audiovisual la dificultad que lleva consigo la traducción del humor. Como dice Ioppi:

The question regarding translation in the extent to which humour (in its various aspects) can be transferred from one language to another and how. [...] Since cognitive schemes vary from one individual to another we cannot expect a joke to have the same effect upon different individuals and in different cultures. That is humour, being culture-specific, is so difficult to translate. In fact almost everything regarding translation involves differences in culture, but the bid challenge concerning humour is not only to keep the meaning of a joke but also to provoke the same effect without compromising the text cohesion and coherence (1999: 167-168).

Por una razón estrictamente práctica partimos de una concepción amplia de humor audiovisual capaz de incluir todos los elementos verbales o no verbales, implícitos o explícitos cuyo fin sea producir humor. Consideramos, coincidiendo con la interpretación de Fuentes Luque (2000: 61), que la unidad de traducción es el texto audiovisual completo y que, si este es de género humorístico, se deberá tener en cuenta como un todo para realizar el análisis y constituir la versión en lengua meta.

Dos son los componentes básicos que intervienen a la hora de trasladar el humor de una lengua a otra: el lingüístico y el cultural. En este punto están de acuerdo numerosos autores que, como Chiaro (1992: 77), tratan la indisolubilidad de lengua y cultura. De este modo, el hecho de tener el mismo código lingüístico es insuficiente si no existe un acervo cultural compartido, 
lo que no quiere decir, como afirma Fuentes Luque (2000: 38), que no existan "universales humorísticos" ligados a "temáticas humorísticas universales". Para este autor, el humor, en sí, es universal, el lenguaje humorístico y los marcos de referencia, sin embargo, no lo son.

No son pocos los autores que han trabajado en la creación de taxonomías del humor para su traducción, así como acerca de los referentes culturales. Por cuestiones de espacio mencionaremos a Raphaelson-West, quien realiza una taxonomía para la traducción de humor, en general, y a Zabalbeascoa, quien lo hace para la traducción del humor en traducción audiovisual, en particular. Raphaelson-West (1989: 130) divide el humor en lingüístico, cultural y universal. Por su parte, Zabalbeascoa (2001b: 26-262) realiza una taxonomía más exhaustiva en la que considera siete tipologías de chiste: chiste internacional, chiste cultural-institucional, chiste nacional, chiste lingüístico-formal, chiste no verbal, chiste paralingüístico y chiste complejo. En el campo de los referentes culturales citaremos a las autoras italianas Bovinelli \& Gallini (1994: 89-98), que ofrecen la siguiente categorización: nombres de localidad geográfica, unidades de medida, instituciones, comidas y bebidas, juegos y entretenimiento y, por último, proverbios y dichos; y a Newmark (1988: 95), cuya clasificación es mucho más exhaustiva.

La traducción del humor en el medio audiovisual ha llevado también a numerosos investigadores a crear necesarias taxonomías en lo relativo a las estrategias de traducción del humor y de los elementos culturales. Muestra de ello es la propuesta de Fuentes Luque (2000: 59-61), quien conjugando diversas clasificaciones realizadas por autores tales como Nash o Delabastita, distingue entre juegos de palabras y de ideas. Los primeros, relacionados con el humor del lenguaje, y los segundos con el del contexto. Además, distingue las siguientes estrategias: traducción literal, traducción explicativa, traducción compensatoria y traducción efectiva o funcional.

En cuanto a los trabajos que abordan la traducción de elementos culturales destacamos los de Franco Aixelà (1996: 107-123) y Agost (1999: 99-102). Franco Aixelà propone dos polos fundamentales: la conservación y la sustitución de los elementos culturales. A su vez, estos dos bloques se subdividen en seis estrategias por bloque. La segunda autora, Agost, a diferencia de Franco, propone solo cuatro estrategias principales de traducción de los elementos culturales específicos: adaptación cultural, traducción explicativa, supresión y sustitución y, finalmente, no-traducción. 


\section{Análisis del corpus}

\subsection{La película}

El Espantatiburones narra la historia de Oscar, un joven pez que trabaja en un taller de lavado de ballenas y que sueña con ser rico. Cabe destacar igualmente la historia de Lenny, un tiburón cuyo padre se llama Don Lino, jefe de la banda de tiburones de un arrecife. Don Lino está deseando delegar el mando en sus dos hijos, Lenny y Frankie. Sin embargo, Lenny es un tiburón muy dulce y diferente, incapaz de comer peces.

Lenny y Oscar se encuentran en el momento en que Oscar está a punto de ser asesinado por el impago de un préstamo. Justo en ese momento aparecen Lenny y su hermano Frankie, quien pretende educarlo para convertirlo en un tiburón feroz. En ese marco tiene lugar un desafortunado accidente: la caída de un ancla mata a Frankie. Debido a una confusión todo el arrecife cree que fue Oscar quien, tras enfrentarse a Frankie, logró vencerle. De esta manera Oscar se convierte en el Espantatiburones, un héroe que por fin tiene todo lo que había soñado. Cuando Don Lino tiene conocimiento del supuesto asesinato de su hijo, pide a sus camaradas que encuentren a su asesino a toda costa. Oscar y Lenny trazarán un plan para ayudarse mutuamente y evitar que Don Lino acabe con él, contando para ello con la ayuda de su compañera de trabajo Angie, que siempre ha estado perdidamente enamorada de Oscar.

\subsection{Versión original y versión doblada}

El Espantatiburones cuenta en su versión original con las voces de famosos actores estadounidenses. Además, los personajes son caricaturas de estos actores. El reparto queda de la siguiente manera en la versión original (V.O.), en inglés, y en la versión doblada (V.D.), en español:

\begin{tabular}{|c|c|c|}
\hline Personaje & Voz $^{1}$ (V.O.) & Voz $^{2}$ (V.D.) \\
\hline Oscar & Will Smith & Fernando Tejero \\
\hline Angie & Renée Zellweger & María Adánez \\
\hline Lola & Angelina Jolie & Natalia Verbeke \\
\hline Don Lino & Robert De Niro & José Sancho \\
\hline Lenny & Jack Black & Alberto Mieza \\
\hline Sykes & Martin Scorsese & Santiago Ramos \\
\hline
\end{tabular}

1. http://www.sharktale.com/main.html

2. www.eldoblaje.com 


\begin{tabular}{|c|c|c|}
\hline Katie Current & Katie Couric & Mercedes Milá \\
\hline Ernie & Ziggy Marley & Marc Zanni \\
\hline Bernie & Doug E. Doug & Raúl Llorens \\
\hline Frankie & Michael Imperioli & Xavier Fernández \\
\hline
\end{tabular}

Para realizar el análisis de El Espantatiburones, hemos partido de la lectura del guion original de la película. Una vez comprobada la correspondencia entre el guion y el visionado, hemos atendido a la película original para hallar los recursos humorísticos y los referentes culturales empleados en el guion original. De este modo, hemos procedido a una primera clasificación del humor y de los referentes culturales ${ }^{3}$ siguiendo la taxonomía de Zabalbeascoa (2001b). Posteriormente, se ha procedido a analizar la versión doblada al español para comprobar qué estrategias de traducción se han empleado para el doblaje de los elementos humorísticos y referentes culturales analizados en primera instancia en la V.O. Para esta segunda tarea, hemos empleado la clasificación de Fuentes Luque (2000). La motivación que nos lleva a realizar dicho análisis se puede resumir en dos objetivos: a) observar qué estrategias de traducción se han empleado para tal empresa y b) si estas han sido acertadas para conseguir el propósito de trasladar el humor a la lengua meta.

\subsection{Clasificación del humor y referentes culturales para la traducción}

En primer lugar, procedemos a la clasificación de los elementos humorísticos detectados, un total de veintiuno, tomando como referencia la taxonomía de Zabalbeascoa (2001b: 26-262):

\begin{tabular}{|c|c|}
\hline Categoría & Cantidad \\
\hline Chiste internacional $^{4}$ & - \\
\hline Chiste cultural-institucional $^{+}$ & 4 \\
\hline Chiste nacional & - \\
\hline
\end{tabular}

3. Hemos decidido utilizar únicamente la taxonomía de Zabalbeascoa tanto para el humor como para los referentes culturales, puesto que, a excepción de un ejemplo de referente cultural, que hemos desestimado, el resto se basa en los referentes culturales para dar como resultado una escena cómica.

4. El chiste internacional es aquel que se entiende entre un grupo limitado de lenguas y culturas. (cf. Zabalbeascoa 2001b). No hemos tenido en cuenta este tipo de chiste para el análisis de este trabajo por cuestiones de espacio, ya que la cultura occidental tiene muchos elementos en común y, por lo tanto, abundan en la película. Nos ha parecido más interesante centrarnos en aquellos chistes cuya traducción es más tediosa. 


\begin{tabular}{|c|c|}
\hline Chiste lingüístico-formal & 11 \\
\hline Chiste no verbal & - \\
\hline Chiste paralingüístico & 3 \\
\hline Chiste complejo & 3 \\
\hline
\end{tabular}

Como podemos observar en la tabla, los elementos humorísticos con mayor número de repetición en nuestro análisis fueron los chistes lingüístico-formales (11), seguidos de los chistes cultural-institucionales (4), paralingüísticos (3) y complejos (3). Cabe destacar que los chistes complejos presentaron las siguientes combinaciones: a) internacional y paralingüístico y b) cultural-institucional y lingüístico-formal.

\subsection{Clasificación y análisis de las estrategias de traducción}

En la bibliografía acerca de la traducción del humor en el campo audiovisual hemos comprobado que existen diferentes clasificaciones sobre las posibles estrategias traductoras. Para conseguir nuestro primer objetivo llevamos a cabo un análisis basado en los elementos humorísticos y culturales que hemos detallado numéricamente en el apartado anterior, teniendo en cuenta la propuesta clasificatoria de Fuentes Luque (2000: 59-61), quien distingue las posibilidades siguientes: traducción literal, traducción explicativa, traducción efectiva o funcional y traducción compensatoria. A esta taxonomía añadimos una quinta estrategia que tomamos de la clasificación de Agost (1999): la no-traducción.

Para cumplir con nuestro segundo objetivo, comprobaremos si la traducción de los elementos humorísticos ha sido realizada con éxito o no, y valoraremos para cada ejemplo si la equivalencia propuesta por los traductores es una equivalencia pragmática, ${ }^{5}$ es decir, si produce en el receptor meta el mismo efecto que el original o, si por el contrario, hay equivalencias que se ciñen a la correspondencia denotativa perdiéndose, de este modo, la intensidad del efecto humorístico en el destinatario meta.

5. Koller (1979, cit. en Ponce Márquez 2008) establece 5 tipos de equivalencias: a) Equivalencia denotativa (denotative Äquivalenz): correspondencias léxicas; b) Equivalencia connotativa (konnotative Äquivalenz): buscar equivalencias a las connotaciones que aparecen en el texto; c) Equivalencia normativa textual (textnormative Äquivalenz): mantener la normativa lingüística y textual en determinados tipos de texto (contratos, cartas comerciales...); d) Equivalencia pragmática (pragmatische Äquivalenz): el texto traducido debe producir en el receptor el mismo efecto que el texto original; y e) Equivalencia formal (formale Äquivalenz): en determinados textos se deben respetar las propiedades estéticas y estilísticas (rima, estrofas...). 


\subsubsection{Traducción literal}

La traducción literal, como su propio nombre indica, consiste en traducir palabra por palabra. Es un tipo de traducción que puede causar desconcierto en el receptor del texto meta al no comprender dónde está la gracia. Por el contrario, en ocasiones puede funcionar muy bien.

De los veintiún elementos humorísticos analizados, tres han sido traducidos mediante la traducción literal. Los detallamos a continuación:

Ejemplo 1 (00:12:48). Se realiza una alteración léxica en una colocación.

[Oscar] Hey, baby, this is all gravy today. Hey, tío, yo estoy que flipo.

Now snap your fin... Snap it. Choca esa aleta... chócala.

- You're not snappin' it...

- No lo estás haciendo...

El mensaje no nos sorprende, ya que la imagen es acorde con lo que estamos escuchando. En la V.O. se dice snap your fin y el traductor opta por la traducción literal choca esa aleta para la V.D. En este caso, tanto el espectador de lengua inglesa como el de lengua española recibirán la misma información y con el mismo grado humorístico respaldado por la imagen que lo ilustra.

Ejemplo 2 (00:14:12). El jefe de Oscar le está reclamando el dinero que le debe.

[Sykes] That's your problem. Bring my clams to the track tomorrow, or else...
Es problema tuyo. Me llevas mañana 5.000 chirlas al hipódromo o si no...

Haciendo alusión a la versión original, debemos decir que utiliza la palabra clams 'almeja' para referirse al dinero. Sin embargo, en la V.D. el traductor utiliza chirlas. La definición que el DRAE nos ofrece de chirlas es la siguiente: 1.f Molusco lamelibranquio bivalvo parecido a la almeja, pero de menor tamaño. Con estos datos podemos decir que en la V.D. el traductor opta por utilizar un hipónimo chirla mientras que en la V.O. se utiliza el hiperónimo almeja. Sin embargo, esta elección nos parece muy adecuada, ya que en la versión española queda muy natural, se mantiene el juego de palabras y llega el mensaje al espectador español.

Ejemplo 3 (00:22:15). Las dos medusas que trabajan para Sykes, el jefe de Oscar.

[Bernie] Oscar, you cute, but you're a nobody.

[Ernie] Wait. Lola. Come back. I'm not a nobody. I'm a wiener.
Oscar, eres mono, pero eres un Don nadie.

Espera. Lola. Vuelve. No soy un Don

Nadie. Soy una salchicha. 
Bernie y Ernie parodian la escena precedente en la que Lola, un pez oportunista de la zona rica, se da cuenta de que Oscar no tiene dinero y lo desprecia. Las medusas reproducen el diálogo entre Oscar y Lola representado con dos salchichas. Como se puede apreciar, en la V.O. existe un ingenioso juego de palabras vinculado a la imagen. Se utiliza la palabra wiener que significa salchicha y que se corresponde con la imagen. Al mismo tiempo, wiener es un parónimo de winner 'ganador' que contrasta con nobody y que en realidad sería lo que el protagonista quiere decir realmente, ya que en ese momento acaba de apostar el dinero que le debe a su jefe a un caballito de mar de una carrera que se va a desarrollar en ese mismo lugar.

En la traducción al español, el traductor, limitado por la imagen, ha optado por traducir literalmente no soy un Don Nadie soy una salchicha. Al espectador no le parece raro escuchar la palabra 'salchicha' puesto que la está viendo en la pantalla. Sin embargo, toda la carga humorística e ingeniosa de la versión original que relaciona en un solo segundo el hecho de ser campeón frente a ser un Don Nadie y el juego fonético wiener /winner sumado a la imagen, se queda a medio camino en la versión doblada.

\subsubsection{Traducción explicativa}

La traducción explicativa es aquella en la que se traslada el significado, pero se pierde el sentido o el efecto humorístico. De esta manera, los tres ejemplos que siguen esta estrategia de traducción no obtienen como resultado una equivalencia pragmática.

Ejemplo 4 (00:11:18). Se muestra un ingenioso juego de palabras.

[OSCAR] Welcome to Oscar's crib. -foot slime-covered tongue with canker sores, swim-in cavities, and plankton-encrusted teeth for when I feel a bit... [grunts] old school.
Bienvenidos al cuchitril de Oscar. Veinte metros de lengua cubiertos de aftas, restos de comida, profundas caries y sarro para exportar, para cuando me siento un poco... depre.

En la V.O., Oscar, el protagonista de la película, está limpiando la boca de una ballena en la que vemos algas y plancton. Él empieza a hablar diciendo plankton-encrusted teeth. Aquí se hace un juego de palabras con plankton y plaque (plancton en lugar de sarro) aprovechando la similitud fonética de los términos en inglés y jugando con el sema visual. La V.D. traduce planktonencrusted por sarro perdiéndose, de este modo, la gracia del juego de palabras. El espectador español ignorará totalmente que allí existía un chiste lingüístico. 
Así, a pesar de que el mensaje le llega sin ningún tipo de problema, no lo hace la carga humorística que encierra la versión original.

Ejemplo 5 (00:03:05). Se observa un juego fonético.

[JANICE] Thanks, Katie. Slight congestion here on the InterReef. There's an overturned mackerel. Authorities are trying to calm him down. Get out those shell phones and call in to the boss, 'cause you'll be late.
Gracias Katie. Hay un embudo en la Intercoral 95 donde ha volcado una caballa. Las autoridades intentan calmarla. Cojan el móvil y llamen al jefe, van a llegar tarde.

En la V.O. una de las corresponsales para la TV está informando sobre lo sucedido en el lugar de los hechos y comenta que hay atasco y que mejor que usen los cell phones 'teléfonos móviles' para avisar de que llegarán con retraso. Para adaptar cell phone al mundo submarino en el que se desarrolla la película se utiliza el siguiente juego de palabras shell phone 'teléfono-concha'. En la versión en español se traduce por móvil perdiendo así toda connotación humorística con respecto al ambiente que recrea la película.

Ejemplo 6 (00:43:15). Toma como referente cultural un equipo de baseball de Texas que lleva por nombre Texas Sharks.

[LENNY] Now batting for the Southside Y bateando para los Tibushocks... Sharks...

Como podemos observar, en la V.O. adaptan el equipo de baseball de Texas Sharks a Southside Sharks. Southside es el nombre de la ciudad donde viven los protagonistas de la película. Además, el hecho de que hayan escogido este equipo no debe ser casual, ya que también lleva en su nombre un componente propio del mundo submarino sharks 'tiburones'.

En la V.D. se ha optado por inventar el nombre de un equipo que lleve parte de la palabra tiburón dando así la palabra Tibushocks que no tiene ningún referente cultural como tal. Además, se mantiene el deporte del baseball en lugar de utilizar otro referente cultural más próximo a los españoles como podría ser el fútbol. Esto podría haberse hecho puesto que solo se escucha la voz de Lenny hablando, pero no hay ningún sema visual que limite la traducción.

Estos tres ejemplos son clara muestra de equivalencia denotativa pero no pragmática, pues el efecto humorístico que se da en el original se pierde en la traducción a pesar de transmitir mensaje. 


\subsubsection{Traducción efectiva o funcional}

La traducción efectiva o funcional consiste en reformular el chiste para conseguir el efecto humorístico del original. De los veintiún ejemplos tres siguen esta estrategia de traducción.

Ejemplo 7 (00: 55:10). Se hace juego fonético, pues el jefe de los tiburones se llama Don Lino.

[OSCAR] Yeah, and you tell Don Lame-o that I don't never, ever, ever, never, want to see another shark on this reef again.

Ever.

Remember this name. Oscar the

Sharkslayer.
Sí. Y tú dile a Don "Limpio" que nunca nunca nunca nunca quiero volver a ver en este arrecife un tiburón. ¡Nunca! Recuerda este nombre. ¡Oscar el Espantatiburones!

En la V.O. se busca la ironía llamando al jefe de los tiburones blancos Don Lame-o, que en jerga urbana quiere decir 'estúpido'. En la versión doblada hay un cambio de dirección en el referente. Si en la versión original la broma se hacía utilizando léxico de la lengua urbana, en la versión doblada la broma utiliza como referente una marca comercial de producto de limpieza que todo español conoce 'Don Limpio'. Así, se mantiene, dentro de lo posible, ese juego fonético que se realiza en la versión original, a pesar de deslocalizar el referente. Al fin y al cabo, la idea básica del traductor es provocar la sonrisa del espectador gracias a una equivalencia pragmática y con la traducción literal probablemente no lo habría conseguido.

Ejemplo 8 (00:07:58). Se aprecia una marca de donuts americana y canadiense deformada.

[Angie] - You didn't. Kelpy Kremes?

¿Sí? ¿Placdonuts?

La marca original es Krispy Kreme. En cambio, en la versión original podemos escuchar Kelpy Kremes. En la versión al español se opta por inventar una palabra en la que aparezca un elemento del mundo submarino junto a otra marca comercial de donuts conocida por el espectador español: placdonuts. 
Ejemplo 9 (00:04:39). Un momento de una escena con un grupo de pececitos del arrecife hablando con Oscar en tono de burla.

[FISH1] 'Cause you so broke, your baloney ${ }^{6}$ has no first name.
Porque si te conocieran, las salchichas solo se llamarían Mayer.

En la V.O. se hace referencia a la marca comercial Oscar Mayer aludiendo a su canción publicitaria en Estados Unidos. Por tanto, la frase de la canción en la escena de la película, fuera de ese contexto publicitario, crea un doble juego humorístico: por una parte, el espectador anglófono la asocia a la canción; por otra parte, da a entender que, de ser por Oscar, las salchichas dejarían de llevar ese nombre.

En la V.D., debido a que el público español no conoce la canción, se pierde una parte de ese doble juego humorístico. A pesar de ello, la equivalencia es pragmática, aunque parcial, pues se crea una sonrisa en el espectador español, al captar inmediatamente la broma que el pez está haciendo con respecto a Oscar y a la marca comercial Oscar Mayer.

\subsubsection{No-traducción u omisión}

Hemos considerado necesario añadir a la clasificación de estrategias de traducción de Fuentes Luque un apartado de no-traducción, tras haber encontrado doce ejemplos, de los veintiuno analizados, en los que los traductores optan por la no-traducción.

Ejemplos 10, 11, 12 y 13 (00:02:58). Al inicio de la película, en pantalla aparece una estrella de mar presentando a varios famosos en un contexto que simula el Paseo de la Fama de Hollywood. En él se aprecian las populares estrellas con nombres de cantantes mundialmente conocidos. Sin embargo, gracias a la alteración de algunas letras, se crea un juego fonético que hace que sus nombres pasen a designar pescados y moluscos.

$\begin{array}{cc} & \text { [STARFISH] } \\ 10 & \text { Tuna Turner } \\ 11 & \text { Mussel Crowe } \\ 12 & \text { Jessica Shrimpson } \\ 13 & \text { Cod Stewart }\end{array}$

[STARFISH]

Mussel Crowe

Cod Stewart

\author{
[ESTRELLA DE MAR] \\ Tuna Turner \\ Mussel Crowe \\ Jessica Shrimpson \\ Cod Stewart
}

6. Canción: "My baloney has a first name; it's O-S-C-A-R. My baloney has a second name; it's M-A-Y-E-R. Oh, I love to eat it every day, and if you ask me why, I'll say, cause OscarMayer has a way with B-O-L-O-G-N-A". http://www.geocities.com/foodedge/jingles4.html 
Como podemos comprobar en la V.D. los traductores han optado por dejar los nombres sin traducir. De este modo en español hay una pérdida total del humor que se pretendía crear con el juego fonético en inglés donde Tuna significa 'atún'. Con un solo cambio de fonema 'i' por 'u' obtenemos un nombre propio similar al de la cantante Tina Turner, pero haciendo alusión al campo semántico submarino. Con el resto de los nombres sucede lo mismo: se cambia Rusell Crowe por Mussel Crowe 'Mejillón Crowe', Jessica Simpson por Jessica Shrimpson 'Jessica Gamba' y Rod Stewart por Cod Stewart 'Bacalao Stewart'.

Ejemplo 14 (00:03:03). En la misma secuencia del Paseo de la Fama.

[STARFISH]

[seal barks]
[ESTRELLA DE MAR]

Seal

En la V.O. se hace una broma sobre el cantante Seal. Cuando llega el turno de presentar a Seal, la estrella de mar se calla y únicamente se ve la imagen de una foca sobre la estrella del Paseo de la Fama donde también está escrito Seal. En la V.O. se hace un juego visual, pues el cantante responde a ese nombre. Dicho sustantivo como nombre común tiene el significado de foca. Aprovechando que el verdadero nombre del artista coincide con el campo semántico que están explotando en el film lo utilizan de manera humorística.

El primer cambio que existe en la versión española con respecto a la versión original es que la estrella de mar sí pronuncia el nombre de Seal mientras vemos la imagen de la foca en la pantalla. Sin embargo, a pesar de escucharlo, el destinatario meta, a menos que tenga conocimiento de la lengua inglesa, no relacionará que el nombre que se pronuncia combinado con la imagen pretende hacer un chiste de adaptación al mundo marino. Consideramos que este tipo de humor es uno de los más difíciles de traducir, ya que combina un referente cultural, el léxico y el sema visual, lo que limita enormemente las posibilidades de adaptar la broma.

Ejemplo 15 (00:02:32). Se alude a una presentadora de informativos muy conocida en Estados Unidos, Katie Couric.

[Katie Current] You sure? Good morning, Southside Reef. I'm Katie Current, keeping it current. We've received official confirmation the sharks are gone.
¿Seguro? Buenos días, pecevidentes soy Katie Current la que os cuenta lo que ocurre. Acabamos de recibir la confirmación de que los tiburones se han ido. 
Siguiendo con los referentes culturales, vemos cómo se efectúa un juego de palabras con el apellido real de la presentadora Couric por Current 'corriente marina'. En la versión española tanto el nombre como el apellido han quedado igual con lo cual se pierde el juego de palabras que el espectador anglófono capta en la versión original. Sin embargo, la voz que ha doblado al personaje de Katie Current es la de Mercedes Milá, una presentadora muy conocida en España. Con esto queremos decir que, al menos, el efecto de cercanía entre el espectador y la voz de la presentadora que está viendo en pantalla se consigue en ambos casos: en la versión original y en la doblada. La diferencia es que en la versión original confluyen la voz, el juego de palabras del apellido y la imagen que hace una caricatura de la presentadora Katie Couric convertida en pez.

Ejemplos 16, 17 y 18 (00:02:52 / 00:03:06 / 00:03:41). Atañen al mismo problema humorístico que el anterior, pero se limitan únicamente al sema visual y al lenguaje escrito.

16

17

18
Starfish tours

don't swim // swim

Prawn Shop

We Sell Quality Stolen Goods
No aparecen subtítulos

Recordemos que en El Espantatiburones se crea un mundo paralelo que adapta hasta el mínimo detalle al mundo submarino. Prueba de ello son las numerosas referencias a este mundo que podemos ver a lo largo de la película: en los carteles de las tiendas o en la adaptación de marcas comerciales. Somos conscientes de que, incluso en la versión original, el espectador no percibe particularmente uno a uno estos detalles. Sin embargo, hemos encontrado tres casos en los que aparecen primeros planos de algunos carteles que pueden hacer que el espectador español se quede con la curiosidad de saber qué decían. Además, se les hace primeros planos porque realmente tienen juegos de palabras y son humorísticos.

En el primer ejemplo Starfish tours aparece escrito sobre un pez con forma de autobús y aparece en primer plano durante varios segundos. Al no existir subtítulo que indique la traducción al español, el espectador español queda indiferente ante el juego de palabras.

En el segundo ejemplo swim// don't swim aparece en un semáforo que controla el tráfico de los peces. Es cierto que en la versión doblada el espectador comprende al instante que se trata de un semáforo y que, como está en rojo, los peces deben detenerse y reiniciar el movimiento cuando en la pantalla se 
aprecia el color verde. Visto así, la imagen habla por sí sola y transmite el mensaje. Sin embargo, no transmite el humor de nade, no nade que el espectador anglófono sí percibe.

En el tercer ejemplo Prawn Shop. We Sell Quality Stolen Goods tampoco aparecen subtítulos indicando la traducción al español. En este caso, al igual que en los dos anteriores se pierde el juego de palabras buscado. Prawn en inglés significa 'gamba'. De hecho, el dueño de la tienda es una gamba. Sin embargo, por las imágenes que continúan y la segunda parte del letrero de la tienda We Sell Quality Stolen Goods podemos deducir que está haciendo un juego de palabras imitando Pawnshop que significa 'casa de empeños'. Este ingenioso chiste está de más para el espectador español que únicamente ve una imagen donde aparece una gamba. Probablemente no le dirá nada, ya que para él será un personaje más del mundo submarino donde se desarrolla la historia.

Ejemplos 19 y 20 (00:55:26 / 00:55:29).

19

20
Coral-Cola

Fish king
No aparecen subtítulos

Al igual que en los casos anteriores, ninguno de estos dos ejemplos (19 y 20) están subtitulados en la V.D. Con respecto al 19 Coral-Cola no hay ninguna duda de que el espectador español va a captar el juego de palabras por dos razones: 1. El término coral es idéntico al español. 2. El anuncio de Coca-Cola es universal y reconocible por los espectadores españoles.

En el caso de Fish king un juego de palabras con la cadena de restaurantes de comida rápida Burger King. No aparecen subtítulos a pesar de salir en un primer plano. Sin embargo, debido a la gran cantidad de restaurantes americanos de comida rápida existentes en España que mantienen los nombres de sus productos en inglés, no es de extrañar que los espectadores españoles conozcan palabras tales como chicken o fish. De ahí que puedan entender el juego de palabras que están viendo.

Sin embargo, nos llama la atención que en el minuto 00:35:06 Oscar está en un ascensor y en primer plano aparece penthouse subtitulado como 'ático'. Consideramos que, al igual que se ha subtitulado 'ático' se deberían haber subtitulado los ejemplos anteriores que no solo daban una información, sino que contenían carga humorística. 
Ejemplo 21 (01:03:00). Luca, el ayudante de Don Lino, llama a Oscar para decirle que Angie, la compañera de trabajo que siempre ha estado enamorada de él, está secuestrada.

[LUCA] Be there if you don't wanna see Si no vas te la encontrarás durmiendo entre her sleepin' with the fishes. The dead ones. los peces. Los muertos.

En esta conversación encontramos el referente cultural, sleeping with the fishes, que tiene varias interpretaciones: 1 . un álbum de canciones para niños que responde al mismo título. 2. el título de un libro que trata sobre gánsteres. Además, debido al léxico que utiliza, viene como anillo al dedo para la versión original.

En la V.D. se traduce literalmente y dice durmiendo entre los peces. De este modo, el mensaje original sí llega a los espectadores españoles, pero no llega la carga humorística y cultural que tiene en la V.O.

\subsubsection{Traducción compensatoria}

La traducción compensatoria consiste en verter el humor en otro sitio distinto para compensar las pérdidas que pudiera haber a lo largo de la traducción de la película. Harvey (1995: 66) define la compensación como "a technique for making up for the loss of a source text effect by recreating a similar effect in the target text through means that are specific to the target language and/or to the target text". Chaume (2008: 75) entiende la compensación como "[...] estrategia que permite superar las restricciones con las que se enfrentan los traductores de textos audiovisuales". A su vez, habla de cinco tipos de restricción (2008: 76) en la traducción audiovisual: restricciones profesionales, formales, lingüísticas, socioculturales y semióticas o icónicas.

El análisis previo, acerca del tipo de humor empleado en la película que nos concierne, esclarece que las restricciones predominantes son las lingüísticas, socioculturales y semióticas. Las primeras representadas por los juegos de palabras; las segundas, por los referentes culturales y las terceras, por el condicionamiento que, en ocasiones, ha ofrecido la imagen. Chaume (2008) especifica que la compensación se utiliza para superar, precisamente, estos tres tipos de restricciones. Por lo tanto, las compensaciones aplicadas por los traductores están justificadas. 
Queremos destacar que los doce ejemplos contenidos en esta sección son complementarios a los analizados en los apartados anteriores. ${ }^{7}$ Como es lógico, estos han sido detectados en la versión doblada, pues el traductor ha decidido poner una pincelada de humor en lugares de la película donde el original no lo hacía. De esta manera, buscan compensar las pérdidas que se hayan podido causar en otros momentos.

Agruparemos las compensaciones que hemos encontrado en tres grupos: verbales, pluriverbales y socioculturales.

\subsubsection{Verbales}

Al trabajar con la versión doblada, hemos detectado que el traductor ha buscado plasmar vocabulario del mundo submarino en lugares donde el original no lo hacía. No debemos olvidar que la película refleja una urbe en las profundidades del océano que nos recuerda enormemente a la ciudad norteamericana de Nueva York, y crea un ambiente totalmente marino en el que las marcas comerciales, los apellidos e incluso el lenguaje de los protagonistas se deformaba y se adaptaba al mundo submarino. Veamos los siguientes ejemplos.

Ejemplo 22 (00:04:25). Oscar está haciendo propaganda de sí mismo.

[OSCAR] 'Cause even a superstar Mack daddy fish like me has to have the basic necessities.
Porque incluso una pecebridad, un pez súper ligón como yo no puede olvidar lo más necesario.

En la V.O. dice superstar 'superestrella' mientras que en la versión doblada se traduce por pecebridad que es, en realidad, una palabra inventada o coinage que adapta la traducción al mundo marino. Vemos una clara deformación fonética de la palabra celebridad. Con este ejemplo comprobamos que el traductor es consciente de que, durante la película, ha habido muchos casos en los que no ha podido mantener los juegos de palabras, los juegos fonéticos, visuales... y aprovecha en esta escena para introducir uno de ellos.

Ejemplo 23 (00:08:27). Don Lino, el jefe de los tiburones blancos, está hablando a las pirañas que tiene en un acuario y se dirige a ellas diciéndoles little babies.

[DON LINO] How are my little babies this morning? You miss me? You doin' good?
¿Cómo están hoy mis pezqueñines? ¿Me echabais de menos? ¿Va todo bien, eh?

7. Por este motivo los volveremos a enumerar desde el número uno. 
En el ejemplo 23 vemos de nuevo que el traductor ha actuado realizando una compensación. En la V.D. se hace referencia a un anuncio difundido en España sobre la conciencia a la hora de pescar peces pequeños. En esta publicidad a los peces pequeños les llaman pezqueñines y el traductor aprovecha que este anuncio es muy conocido por la sociedad española para compensar las pérdidas anteriores. Recordemos que anteriormente analizábamos una frase de la película original que hacía alusión a un anuncio publicitario de las salchichas Oscar Mayer y que en su traducción al español se perdía la conexión con el mismo. Aquí tenemos un ejemplo de compensación en la que, en otra parte de la película, el espectador español asociará la palabra que escucha con un anuncio propio de su país. En los ejemplos siguientes la compensación versa sobre expresiones pluriverbales deformadas.

\subsubsection{Pluriverbales}

Ejemplo 24 (00:09:33). Don Lino está haciendo una especie de monólogo y llega un momento en el que dice Long story short 'resumiendo'.

[DON LINO] Long story short, from now on you work for Frankie and Lenny.
No me iré por las algas, ahora trabajas para Frankie y Lenny.

En la versión doblada aprovechan para introducir la locución verbal española irse por las ramas, pero adaptándola al mundo marino.

Ejemplo 25 (00:11:04). En la escena aparece Oscar limpiando la lengua de una ballena mientras habla con sus compañeros de trabajo, uno de ellos pasa por detrás y le dice:

[OSCAR] Who's behind me? Whoever's behind me better give me some.
¿A quién tengo detrás? El que esté detrás que choca esa aleta.

Ejemplo 26 (00:16:06). Oscar está hablando con Angie y lamentándose porque le debe mucho dinero a su jefe Sykes. Angie le dice que no se preocupe y Oscar responde:

[OSCAR] What's the difference? If I don't pay Mr. Sykes back by tomorrow... I'm dead anyway, so...
Qué más da. Si mañana no le pago al Sr. Sykes lo que le debo... soy pescado muerto 
Ejemplos 27, 28, 29 y 30 (00:39:03 / 00:50:15 / 00:52:06 / 00:56:00). Se alteran expresiones pluriverbales en la V.D. que en la V.O. aparecen totalmente impolutas.

\begin{tabular}{|c|c|c|}
\hline 7 & [LINO] Where the heck is he? Lenny! & ¿Dónde centollos está? \\
\hline & $\begin{array}{l}\text { [OSCAR] All right, look, I'm sorry. } \\
\text { I totally betrayed you, but listen, I got } \\
\text { just one little problem I gotta take } \\
\text { care of. }\end{array}$ & $\begin{array}{l}\text { Está bien, lo siento. Me he portado } \\
\text { como un congrio. Pero ahora tengo que } \\
\text { resolver un problema. }\end{array}$ \\
\hline & $\begin{array}{l}\text { [KATIE CURRENT] Holy mackerel. } \\
\text { Did we get that? }\end{array}$ & $\begin{array}{l}\text { ¡Por todos los centollos! ¿Lo habéis } \\
\text { cogido? }\end{array}$ \\
\hline & $\begin{array}{l}\text { [KATIE CURRENT] Seems The } \\
\text { Sharkslayer not only conquered a few } \\
\text { sharks today, but maybe a few hearts? } \\
\text { Has the reef's most eligible bachelor } \\
\text { been snapped up? }\end{array}$ & $\begin{array}{l}\text { Parece que el Espantatiburones no solo } \\
\text { ha conquistado a los escualos, sino } \\
\text { también algún corazón. ¿El soltero } \\
\text { más cotizado del arrecife ha caído en } \\
\text { las redes? }\end{array}$ \\
\hline
\end{tabular}

Las traducciones literales serían respectivamente: '¿Dónde demonios está?', ‘ $\mathrm{Me}$ he portado como un estúpido!', ‘Por todos los santos!' y "no dejar escapar'. Pero los traductores optan por la compensación.

\subsubsection{Socioculturales}

Ejemplos 31, 32 y 33 (00:27:24 / 00:29:44 / 00:31:25). Recordemos que El Espantatiburones realiza una caricatura de los actores que ponen la voz a sus personajes imitando sus rasgos, sus gestos y aspecto físico.

31 [OSCAR] Just get it over with. Wait a minute. Do me a favor, don't chew me.

32 [OSCAR] Exactly how it look, that's how it is. [OSCAR] I don't think so.
Acaba de una vez. Espera. Un poquito de por favor. No me mastiques.

Es justo lo que parece, tal que así.

¡Ah no! Ni de coña.

En el caso de la V.O., la voz del protagonista es la de Will Smith. En la V.D., la voz protagonista es la del actor español Fernando Tejero. Poco se puede hacer para compensar la imitación de los rasgos, de los gestos y del aspecto físico, pues estas vienen dadas por la imagen. Sin embargo, puesto que el receptor meta reconoce, mediante la voz, al actor de la V.D., el traductor tiene la posibilidad de compensar mediante el lenguaje al introducir frases propias del actor de doblaje en la lengua meta. 


\section{Conclusión}

Una vez finalizado el análisis de los veintiún ejemplos de tipo de humor detectado en la V.O. y de las estrategias de traducción empleadas para su traslación a la lengua meta, nos disponemos a realizar una síntesis de los resultados obtenidos.

Nuestro primer objetivo era reconocer qué estrategias de traducción habían sido las más utilizadas en el doblaje de El Espantatiburones. Sorprendentemente, hemos detectado que la no-traducción ha sido el recurso más empleado en doce de los veintiún ejemplos analizados. Las traducciones literal, explicativa y efectiva o funcional se han empleado en tres ocasiones cada una.

El segundo objetivo se centra en mostrar el tipo de equivalencia predominante tras aplicar las estrategias de traducción mencionadas en el párrafo anterior. Para ello hemos hecho una valoración mediante porcentajes siendo los resultados los siguientes: un $24 \%$ de equivalencia pragmática, $14 \%$ de equivalencia pragmática parcial (solo ha conseguido transmitir parte del efecto humorístico del original) y $62 \%$ de equivalencia denotativa.

Los datos ponen de manifiesto que las diferentes restricciones lingüísticas, socioculturales y semióticas que proliferan en la película han complicado la tarea traductora. Al mismo tiempo, justifican que el traductor haya optado en doce ocasiones por la estrategia de la compensación.

No debemos olvidar que el cine de animación tiene características tales como público joven y amplio margen en la sincronía labial, cosa que proporciona al traductor una mayor libertad a la hora de trasvasar la comicidad subyacente en la película, adaptando el producto a este público meta. Para conseguirlo el traductor debe tener, como ya decíamos anteriormente, un buen conocimiento de ambas lenguas, la del original y la del público meta, pero también de sus culturas y, en casos como la película de El Espantatiburones también debe defenderse en el campo humorístico. Por tanto, el buen resultado de la película ha dependido de la combinación armónica de todos estos factores y conocimientos. Es cierto, que los traductores se han tomado libertad en algunos aspectos, pero siempre con sentido común e interpretando el contexto, siendo siempre conscientes de que existen límites y de que no todo es aceptable.

Para finalizar diremos que consideramos que los traductores han realizado un buen trabajo a pesar de que, en algunos casos, se podría mejorar la traducción, con el fin de evitar algunas de las pérdidas de las que hemos hablado. A pesar de ello, creemos que el resultado final de la versión doblada es bueno y ha funcionado muy bien en el mercado, ya que fue una película que tuvo una gran acogida por parte del público español. 


\section{Referencias bibliográficas}

Agost, Rosa. (1996) La traducció audiovisual: el doblatge. Castellón: Universitat Jaume I. Tesis doctoral inédita.

AgOst, Rosa. (1999) Traducción y doblaje: palabras, voces e imágenes. Barcelona: Editorial Ariel.

BOVINELLI, Bettina \& Serena Gallini. (1994) "La traduzione dei riferimenti culturali nel doppiaggio cinematografico." En: Baccolini, Raffaella; Rosa Maria Bosinelli Bollettieri \& Laura Gavioli (eds.) 1994. Il doppiaggio. Trasposizioni linguistiche e culturali. Bolonia: Editrice CLUEB, pp. 89-98.

Chaume, Fréderic. (2000) La traducción audiovisual: estudio descriptivo y modelo de análisis de los textos audiovisuales para su traducción. Castellón: Universitat Jaume I. Tesis doctoral inédita.

CHaume, Frederic. (2008) "La compensación en traducción audiovisual." Quaderns de Filologia. Estudis literaris 13, pp. 71-84.

CHIARo, Delia. (1992) The language of Jokes. Analysing verbal play. Londres: Routledge.

FrANCO AIXELÁ, Javier. (1996) Condicionantes de traducción y su aplicación a los nombres propios. Alicante: Universidad de Alicante. Tesis doctoral inédita.

FUENTES LUQUE, Adrián. (2000) La traducción del humor audiovisual traducido: estudio comparativo de fragmentos de las versiones doblada y subtitulada de la película Duck Soup, de los hermanos Marx. Granada: Universidad de Granada. Tesis doctoral inédita.

Gambier, Yves (ed.) (1994) Language Transfer and Audiovisual Communication. A Bibliography. Turku: University of Turku.

HARVEY, Keith. (1995) "A descriptive framework for compensation." The Translator 1:1, pp. 65-86.

HurTado Albir, Amparo. (2001) Traducción y traductología. Introducción a la traductología. Madrid: Cátedra.

IOPPI CHILE, Daniela. (1999) "The sitcom revisited: the translation of humor in a polysemiotic text." Cadernos de Traducçao 1: 4, pp. 167-204.

MARTÍNEZ SIERRA, Juan José. (2012) Introducción a la traducción audiovisual. Murcia: Universidad de Murcia.

MAYORAL, Roberto. (2001) "Campos de estudio y trabajo en traducción audiovisual." En: Duro, Miguel (ed.) 2001. La traducción para el doblaje y la subtitulación. Madrid: Cátedra, pp.19-45.

Newmark, Peter. (1988) A Textbook of Translation. Londres: Prentice Hall.

PONCE MÁRQUEZ, Nuria. (2008) "Diferentes aproximaciones al concepto de equivalencia en traducción y su aplicación en la práctica profesional." Tonos. Revista electrónica de estudios filológicos 15. 
RAPHAELSON-WEST, Debra. (1989) "On the Feasibility and Strategies of Translating Humor." Meta 34:1, pp. 128-141.

Santos Redondo, Manuel \& Manuel Moisés Montás Betances. (2010) "Economía de las industrias culturales en español." En: García Delgado, José Luis \& José Antonio Alonso (eds.) 2010. El español, lengua global. La economía. Madrid: Instituto Cervantes.

Zabalbeascoa Terran, Patrick. (2001a) "El texto audiovisual: factores semióticos y traducción.” En: Sanderson, John (ed.) 2001. ¡Doble o Nada! Alicante: Editorial Universidad d'Alacant, pp. 113-126.

Zabalbeascoa Terran, Patrick. (2001b) "La traducción del humor en textos audiovisuales." En: Duro, Miguel (ed.) 2001. La traducción para el doblaje y la subtitulación. Madrid: Cátedra, pp. 251-262.

\section{Bionote / Nota Biográfica}

María LuCía NAVARro Brotons posee una licenciatura en Traducción e Interpretación complementada con un máster en Traducción Literaria y el premio extraordinario de Doctorado en Traducción e Interpretación. Está acreditada igualmente como traductora jurada por el Ministerio de Asuntos Exteriores y Cooperación. Imparte clases de traducción en la Universidad de Alicante desde 2011. Desde 2008 es miembro del grupo de investigación Frasytram, dirigido por el profesor Pedro Mogorrón Huerta. Su investigación se centra principalmente en los temas relacionados con la traducción fraseológica en las áreas del francés y el español.

MARÍA LUCÍA NAVARRO BROTONS holds a degree in Traslation and Interpretation, supplemented with a MA in Literary Translation and the PhD award in Translation and Interpretation. She has also the accreditation of sworn translator issued by the Ministry of Foreign Affairs and Cooperation. She is a lecturer of Translation at the University of Alicante since 2011. Since 2008, she is a member of the research group Frasytram, led by Prof. Pedro Mogorrón Huerta. Her research production focuses primarily on issues related to the translation of phraseological units, especially in the French and Spanish area. 
